\title{
UM ESTUDO HISTÓRICO E ANTROPOLÓGICO SOBRE O FILME BOLIVIANO LA NACIÓN CLANDESTINA ${ }^{1}$
}

\author{
A STUDY HISTORICAL AND ANTHROPOLOGICAL ABOUT THE FILM \\ LA NACIÓN CLANDESTINA
}

\author{
ROSELINE MEZACASA \\ Profa. Ms. da Universidade Estadual de Mato Grosso do Sul - UEMS \\ Mato Grosso do Sul, Brasil \\ roseliemezacasa@hotmail.com
}

\begin{abstract}
Resumo: No presente texto, buscam-se algumas aproximações entre história, antropologia e cinema a partir da análise do filme boliviano "La Nación Clandestina”, produzido pelo cineasta Jorge Sanjinés e lançado em 1989. O filme retrata elementos históricos e culturais do povo Aymara, tendo como protagonista Sebastián, membro deste grupo étnico. Por meio desta personagem principal, o cineasta monta uma trama de tensões e conflitos interétnicos, evidenciando as complexas relações entre indígenas e não indígenas, diante do contexto do golpe militar na Bolívia na década de 1960. Uma característica associada ao cinema produzido por Jorge Sanjinés é o realismo italiano, que almejava produções fílmicas junto ao povo, mostrando as realidades sociais e políticas nos mais variados espaços. O filme busca as relações existentes no interior da comunidade Aymara, sua cosmologia, estrutura de organização social, práticas e rituais feitos pelos indígenas, para, então, fazer o paralelo com a sociedade não índia da Bolívia, que transforma em clandestinidade práticas produzidas há séculos pelos grupos étnicos. Daí o nome "La Nación Clandestina”, pois apresenta uma Bolívia indígena que se torna clandestina dentro de seus próprios territórios imemoráveis. Abordar-se-á essa produção fílmica pelo viés da antropologia do colonialismo, tendo em vista a permanência do colonialismo interno na Bolívia após os processos de independência. O filme é permeado de complexidades e possibilita reflexões importantes para pensar as relações entre os universos indígenas e os não indígenas, dentro de um Estado-Nação que produz no seu interior "nações clandestinas".
\end{abstract}

Palavras-chave: Cinema. Colonialismo. Aymara.

Abstract: In this text, looking up some links between history, anthropology and film from the analysis of the Bolivian film "La Nación Clandestine", produced by filmmaker Jorge Sanjinés and released in 1989. The film portrays historical and cultural elements of the Aymara people, whose protagonist Sebastian, a member of this ethnic group. Through this character, the filmmaker assembles a web of tensions and interethnic conflicts, highlighting the complex relationships between indigenous and non-indigenous, given the context of the military coup in Bolivia in the 1960s. A feature associated with the film is produced by Jorge Sanjinés Italian realism, which aimed to 'films with the people, showing the social and political realities in various spaces. The film seeks to existing relationships within the Aymara community, their cosmology, social organization structure, practices and rituals performed by indigenous, to then make the parallel with the non-Indian society in Bolivia, which turns into hiding practices produced for centuries by ethnic groups. Hence the name "La Nación Clandestine", because it presents a Bolivian native who becomes illegal within their own territories immemorial. Approach will this movie production by the bias of anthropology of colonialism, in view of the permanence of internal colonialism in Bolivia, after the process of independence. The film is riddled with complexities and provides important considerations to think about the relationship between universes indigenous and non-indigenous people within a nation-state that produces inside "clandestine nations."

Keywords: Cine. Colonialism. Aymara.

\footnotetext{
1 Artigo submetido à avaliação em 15 /10/2012 e aprovado para publicação em 28/11 /2012.
} 
[...] por la enajenación de una clase dominante enemiga de su propio pueblo, al que no solamente explota sino también desprecia racialmente. La verdadera Bolivia existe en la clandestinidad; [...].

(SANJINÉS, 1977)

\section{Introdução}

No presente texto, teceremos algumas reflexões iniciais sobre as aproximações entre história, antropologia e cinema a partir da análise e discussão da produção cinematográfica boliviana La Nación Clandestina. O filme denuncia o colonialismo que permanece no interior da República boliviana durante a década de 1960, trazendo alguns elementos históricos e culturais das sociedades indígenas bolivianas, com enfoque nas relações interculturais do povo Aymara com a sociedade nacional boliviana. A história contada em La Nación Clandestina é ficção, entretanto, foi elaborada mediante experiências do cineasta boliviano Jorge Sanjinés, que levou para o cinema um exame minucioso das relações interculturais existentes na Bolívia da década de 1960, tempo em que transcorre o enredo do filme.

A independência da Bolívia ocorreu em 1809. Antes disso, esta faixa territorial que hoje é a Bolívia pertencia ao Vice-Reino do Rio da Prata, submetido à monarquia espanhola. Os espanhóis, já no início dos processos de colonização da América, adentraram aos territórios atualmente bolivianos, iniciando os processos de apropriação territorial. A descoberta do "cerro de plata", em Potosí, por volta de 1545, motivou ainda mais o interesse hispânico por esses espaços da América. Desde então, os espanhóis procuraram intensificar os processos de povoamento, as instalações de estâncias e a evangelização dos ameríndios. Esse projeto colonizador, que perpassou todo o período colonial, deixou profundas marcas em todos os setores da sociedade colonial. Com o processo de independência, essas marcas não foram apagadas, de modo que as características de uma sociedade dual permanecem intrínsecas nas relações após a independência. Sobre a configuração da constituição das sociedades duais, González Casanova (2002) aponta que:

[...] a sociedade dual ou plural resulta do desenvolvimento colonial, caracteriza o crescimento colonial, as relações típicas do 'europeu evoluído' e do 'indígena arcaico', e as formas pelas quais um domina e explora o outro, reforçando suas relações desiguais com processos discriminatórios (GONZÁLEZ CASANOVA, 2002, p. 95).

Nessa conjuntura de relações desiguais, o antigo colonialismo realizado pela metrópole passa a ser interno, constituindo, assim, o que Balandier ([1951] 1993) chamará de "colonialismo interno". Este ocorre quando o processo de independência dessas antigas 
colônias mantém as estruturas da colonização em que indígenas continuam sendo explorados e discriminados pela nova elite que passa a assumir o poder do Estado-Nação.

É fácil e decorrente percebermos o colonialismo interno que se mantém nos países hoje independentes, mas que, por séculos, foram colônias europeias. Nessa conjuntura, surgem esforços para a construção de novas análises, a fim de uma descolonização dos imaginários, das relações humanas desencadeadas no interior desses países. Nesse ponto, queremos chamar a atenção para o cinema produzido na América Latina com o foco nas tradições indígenas. Esse cinema tem contribuído para a visualização dos grupos étnicos espalhados pelo território americano com a proposta de descolonização dos olhares para com os grupos nativos.

No Brasil, a população indígena tem se inserido em grandes projetos de vídeos produzidos pelos próprios grupos étnicos. Nesse sentido, as produções fílmicas tornam-se ferramentas de apoio para a construção da autonomia indígena, como também para a desconstrução do colonialismo interno. Assim, caminha-se em busca de uma autonomia para essas populações. Nesse cenário, os indígenas transformam-se em protagonistas de suas histórias e tradições, levando para as telas dos cinemas um olhar de dentro para fora. Ademais, apresentam para a sociedade nacional aspectos da alteridade coexistente no interior de um Estado-Nação.

Dentro da presente abordagem, procuramos problematizar questões referentes ao colonialismo interno e às relações entre indígenas e não indígenas que o filme produzido por Jorge Sanjinés, La Nacion Clandestina, na década de 1980, traz para o debate. O cineasta, em diálogo com a sociedade Aymara, produziu o filme visando retratar nas telas a realidade social destes indígenas, com propósitos claros de denunciar os dramas vividos por estes.

O diálogo entre cinema e história é profícuo e constitui-se a partir das influências da Nova História. Essa corrente historiográfica, há décadas consolidada nas pesquisas de nossa disciplina, vem utilizando múltiplas fontes e metodologias, com o objetivo de compreender a realidade social. Nesse contexto é que está situado o cinema, fonte importante para a escrita e as reflexões históricas, uma vez que traduz, para as telas,realidades sociais e contextos de determinados grupos sociais e etnias em conjunturas específicas. Desse modo, cabe aos pesquisadores das áreas das ciências humanas a utilização dessa fonte enquanto uma aliada para análises.

Para a historiadora Monica Almeida Kornis, é fundamental destacar a importância da utilização do cinema como fonte histórica para pensarmos determinados períodos e tempos sociais. Segunda a autora, o cinema enquanto fonte histórica adquiriu, 
[...] de fato o estatuto de fonte preciosa para a compreensão dos comportamentos, das visões de mundo, dos valores, das identidades e das ideologias de uma sociedade ou de um momento histórico. Os vários tipos de registro fílmico - ficção, documentário, cinejornal e atualidades vistos como meio de representação da história, refletem contudo de forma particular sobre esses temas. Isto significa que o filme pode tornar-se um documento para a pesquisa histórica, na medida em que articula ao contexto histórico e social que o produziu um conjunto de elementos intrínsecos à própria expressão cinematográfica (KORNIS, 1992, p. 3).

Com base nessas premissas, no decorrer do presente texto, utilizaremos uma produção cinematográfica, fruto de uma ficção, como ponto de partida para pensarmos alguns elementos da história/cultura do povo Aymara, inserido na conjuntura de um Estado Nacional Boliviano que carrega fortes marcas do colonialismo interno, conceito que perpassará toda a nossa discussão.

\section{A Bolívia para além de Evo Morales}

Para muitos brasileiros, a Bolívia é conhecida por ser um país que faz fronteira com o Brasil e ter na presidência da república um representante indígena, eleito por eleições diretas no ano de 2005. No pensamento colonialista, que impera em muitos meios brasileiros, tendo em vista nossa carga ideológica advinda da colonização, justa salvo, pequenos núcleos acadêmicos e sociais que buscam relações mais estreitas com a América Latina, encontramos um panorama em que sujeitos colocam-se de costas para os países americanos, mantendo-se de frente para as nações europeias. Trata-se de estruturas históricas que privam as possibilidades de ultrapassar as fronteiras do pré-conceito sobre os latinos - os Outros -, o que desencadeia uma ausência de integrações culturais na maioria das vezes.

A Bolívia é um país multiétnico, "sendo que $62 \%$ da população se declara indígena" (ANDRADE, 2007, p.17). Vivem no país cerca de trinta e cinco grupos étnicos (VILLARROEL, 2007), entre eles destacam-se, pela densidade demográfica, os quíchuas ( $38 \%$ da população) e os aimarás ( $25 \%$ da população $)^{2}$. Quanto às paisagens bolivianas, estas constam de uma mescla de diferentes ambientes: ao Sul, encontramos o Chaco; ao Norte, a floresta amazônica, e ao centro do país a Cordilheira dos Andes, que divide o território

\footnotetext{
${ }^{2}$ ANDRADE, Everaldo de Oliveira. A revolução Boliviana. São Paulo: UNESP, 2007, p.17.
} 
boliviano em terras baixas e altas. Este conjunto de elementos faz da Bolívia uma expressividade de diversidade étnica e ambiental.

Os territórios que hoje constituem a Bolívia foram "requeridos" pelos espanhóis já no início do século XVI. A descoberta de metais preciosos em Potosí, por volta de 1545, potencializou uma desenfreada corrida pelo metal, tornando o Cerro de Potosí o maior produtor de prata da América durante o período colonial. Enquanto o Cerro de Potosí tornavase o maior fornecedor de prata para a Europa, enriquecendo a metrópole, milhares de indígenas morriam nos trabalhos degradantes das minas.

Desde o início do contato entre ibéricos e etnias indígenas, as relações foram calcadas em violências, opressões e desmantelamentos das estruturas nativas de organização. Contudo, os ameríndios também souberam construir uma história de lutas e resistências ao longo dos processos de colonização de seus territórios. Alguns grupos, como os Chiriguano, resistiram à ocupação dos espanhóis em seus territórios durante todo o período colonial, constituindo-se um empecilho à colonização da região entre o Chaco Boliviano e o pé da Cordillera dos Andes ao sul de Santa Cruz de La Sierra. Já no século XX, como República boliviana, a população de campesinos e trabalhadores potencializaram significativas lutas políticas, tal como a revolução de 1952, articulada pelo Movimento Nacionalista Revolucionário.

Com uma história de lutas e resistências, foi possível, no interior desde país, a eleição do primeiro presidente indígena da América Latina. Essa eleição tem grande significância para a expressiva população indígena do país, a qual, por séculos, foi discriminada e "esquecida" pela elite governamental. Evo Morales, o presidente eleito, cresceu em uma comunidade nos Andes bolivianos, território ocupado tradicionalmente pelos Aymara, grupo ao qual identifica-se etnicamente. A figura de Morales e de sua política administrativa tornou-se uma possibilidade de mudanças e melhorias sociais, além do início da construção de estruturas governamentais menos colonialistas.

\section{Jorge Sanjinés e o Cinema Boliviano}

A conjuntura histórica da Bolívia, detentora de uma trajetória repleta de sistemas econômicos exploratórios, possibilitou o surgimento de um cinema crítico por volta da década de 1950. Nesse mesmo período, o cinema, em vários países do mundo, começava a trazer no bojo de suas temáticas as revoluções políticas e a situação de exploração dos trabalhadores 
nas indústrias capitalistas. No Brasil, o cineasta Glauber Rocha destacou-se nessa linha de produção cinematográfica, tornando-se um expoente do Cinema Novo.

Na Bolívia, durante a década de 1960, um grupo de jovens cineastas, influenciados pelas ideias correntes para além de suas fronteiras, utilizou-se do cinema como uma possibilidade de denunciar a exploração dos campesinos, indígenas e mineiros no interior do país. Entre os jovens estava Jorge Sanjinés, cineasta que produziu o filme La Nación Clandestina. O cineasta, no rol de suas produções fílmicas, construiu uma expressiva trajetória que gira em torno de um cine social que denuncia os problemas existentes no interior de seu país. Dentre os vários trabalhos de Sanjinés, destacamos “Revolución” (1964), filme que trouxe para as telas do cinema uma representação das lutas de diferentes setores da sociedade boliviana, as quais desencadearam na revolução de 1952.

Encontramos, nas produções cinematográficas de Jorge Sanjinés, o neo-realismo italiano com o propósito de levar para as telas a realidade social vivida nas ruas, tornando-se:

[...] um modelo que aproxima o autor da realidade e coloca na tela o povo e a paisagem como protagonistas. Propõe um olhar reflexivo sobre a realidade para além de paradigmas a aparatos técnicos impostos pela indústria cinematográfica (STECZ, 2009, p. 198).

Essas características são recorrentes na obra deste cineasta, tendo em vista o mesmo ter se dedicado a transpor para as telas algumas representações acerca do cotidiano ocorrido no interior da Bolívia. Assim, possibilitou, a partir das imagens cinematográficas, um protagonismo às histórias das populações indígena, campesina e operária. Ademais, mostrou as contradições sociais presentes em seu país, onde grande parcela da população (indígenas, campesinos e trabalhadores) era explorada por uma elite local, resquícios do período colonial.

Construiu Jorge Sanjinés, por meio das telas, uma ferramenta para a luta política que denunciava as desigualdades, os "apagamentos" étnicos e as "clandestinidades" de sujeitos históricos. Como bem ressaltou Stecz, os idealizadores do cinema crítico, fundamentados no neo-realismo, buscavam um "[...] cinema de identidade nacional e de um 'cine junto al pueblo" (STECZ, 2009, p. 203), elementos facilmente encontrados na obra cinematográfica La Nación Clandestina.

\section{O filme La Nación Clandestina: Contextos históricos e antropológicos}


O filme La Nación Clandestina foi lançado no ano de 1989, na Bolívia. Trouxe aspectos históricos da sociedade boliviana durante a década de 1960, cruzando-os com códigos da cultura Aymara, para, assim, levantar o debate das relações interétnicas no interior do país. O filme é composto de um emaranhado surpreendente de informações históricas e antropológicas que se desencadeiam. Assim sendo, não podemos pretender, com nossas análises, esgotar todas as possibilidades interpretativas do filme. Entretanto, queremos levantar o debate sobre algumas questões que consideramos pertinentes no diálogo entre a antropologia, a história e o cinema.

O título dado ao filme - La Nación Clandestina - é enigmático e instigante. Nas palavras do título está elucidada a crítica produzida pelo cineasta às estruturas colonialistas mantidas no interior do território boliviano mesmo depois dos processos de independência. Murillo e Fernández (2002) ajudam-nos a compreender os significados que o título do filme possibilita. Segundo estes autores, o nome atribuído à produção cinematográfica:

[...] hace referencia directa a la existencia de una población indígena que, siendo mayoritaria en el conjunto de la población boliviana, ha sido siempre marginada desde los centros de poder nacionales, constituyéndose en la práctica como una nación dentro de la nación, un pueblo ignorado que pese a mantener sus propias formas de organización se ha visto relegado a una situación de marginalidad, de olvido, de clandestinidad [...] (MURILLO \& FERNÁNDEZ, 2002, p. 81).

O título, por si só, chama a atenção para a relação histórica fundamentada em séculos de exclusão dos grupos étnicos bolivianos das decisões políticas. Essas reflexões caminham e se aproximam da já mencionada discussão feita por Balandier ([1951] 1993) sobre o "colonialismo interno".

Dessa forma, antes e depois da independência, produziu-se um colonialismo com sua força ideológica e política. Para elucidar essas relações, que para nós são colonialistas, o cineasta boliviano apresenta a "situação colonial" pela qual passa o povo Aymara. O conceito de "situação colonial” foi discutido também por Balandier ([1951] 1993) ao caracterizá-lo como um conjunto particular de relações que se funda entre "sociedade colonial" e "sociedade colonizada". Desta relação, aspectos econômicos, políticos, raciais e culturais emergem, configurando, assim, uma dinâmica complexa. Dessa dinâmica, relações de dominação, submissão, resistência e alianças são criadas pelos sujeitos envolvidos nestes processos.

O filme retrata o descaso, o preconceito da população envolvente para com os Aymara, ao mesmo tempo em que apresenta elementos significativos da cultura desse povo, 
mostrando os elementos de resistência criados pelos indígenas. Nesse trânsito de realidades, o cineasta mostra o desconexo existente no ato ideológico de deslegitimar as populações indígenas, uma vez que as estruturas políticas buscaram tornar clandestinos grupos étnicos os quais possuíam riquíssimos códigos culturais - estruturas sociais, cosmologia, língua etc. -, tornando-os clandestinos em seus próprios territórios ancestrais, esquecidos em seus direitos políticos, sociais e territoriais.

No campo do contexto político, o filme aborda o golpe de 1964, momento em que os militares entram no poder na Bolívia desmantelando o governo formado a partir da Revolução de 1952. Durante a revolução de 1952, foi derrubado o poder das oligarquias mineradoras do país, conhecidas como Rosca Mineira, as quais mantinham o domínio das minas desde a independência da Bolívia em 1809. Após a independência da metrópole, o controle da mineração não se desligou completamente do sistema colonial, haja vista que algumas empresas estrangeiras mantiveram o controle das extrações, beneficiando uma pequena elite local, muito vinculada a grupos internacionais.

As mudanças de 1952 propunham a transformação da estrutura política visando a reformas em setores fundamentais do país. Almejaram a nacionalização das minas, o que recuperou este recurso natural que, por séculos, ficou nas mãos de empresas internacionais, como também a reforma agrária, o voto universal, além das reformas educativas. Instalou-se um governo revolucionário com distribuição de armas para formação de milícias campesinas e mineiras, fato que criou a possibilidade da participação de parcelas da população até então excluídas das tomadas de decisões.

Essa luta revolucionária teve a participação de trabalhadores, campesinos e indígenas. O referido governo perdurou por doze anos. Em 1964, ocorreu um golpe militar que instituiu o poder ao General Barrientosk, expulsando o então presidente Víctor Paz Estenssoro, figura importante do Movimento Nacionalista Revolucionário (MNR). O golpe militar colocou um fim aos projetos de cunho social, instalando na Bolívia um governo de ditadura militar. O pano de fundo do filme La Nación Clandestina é exatamente o período de transição do então governo revolucionário para a ditadura dos militares do General Barrientos.

Em primeiro plano está a trajetória caminhante de Sebastián, um índio Aymara, entre a cidade de La Paz e seu ayllu $u^{3}$ tradicional. Essa caminhada é feita pela personagem após alguns acontecimentos decisivos em sua vida. No trajeto entre o universo urbano (La Paz) e o

\footnotetext{
3 Resumidamente, podemos pensar o ayllu como uma comunidade tradicional, e assim sendo, como uma "unidade social andina, que constitui o núcleo das relações sociais e de parentesco, políticas, econômicas e religiosas." (HIDALGO, 2006, p. 115).
} 
rural (seu ayllu), a personagem aciona as memórias das experiências vividas ao longo da vida na cidade, como também as de sua infância no seu ayllu. Ao retomar essas memórias da personagem principal, o cineasta constrói o filme transitando entre o presente de Sebastián (o caminho de La Paz ao seu ayllu) e seu passado (memórias).

Por meio deste jogo de temporalidades entre presente e passado da personagem principal, o cineasta introduz "[...] diversos elementos de confusión entre pasado y presente, fundiéndolos en un tiempo difuso en el que todo ha pasado, todo está pasando y todo está por pasar” (MURILLO \& FERNÁNDEZ, 2002, p. 81). Esses recursos buscam levar para o filme uma representação ao significado do tempo para os Aymara, sendo este um fundir-se entre presente e passado.

\section{Mediações de um Aymara: Mundos que se entrecruzam}

Sebastián vive o drama de muitos indígenas que transitam entre dois mundos: um indígena, de códigos culturais distintos, com o urbano e ocidental. Isso porque, quando criança, por volta de oito/nove anos, Sebastián vai morar com uma família não índia na cidade de La Paz. Esta passagem do filme retrata o processo de "incorporação" deste sujeito a um modo de vida urbano e "não indígena". Contudo, o filme mostra que a "incorporação" ao universo urbano nunca foi completa, pois os elementos do "ser índio" sempre eram destacados nas relações sociais que Sebastián vivia. Essas dinâmicas sociais, permeadas de violências simbólicas, construíram na personagem principal alguns dramas, os quais perpassam todo o enredo do filme.

Sebastián, tendo passado anos morando na cidade, volta para sua aldeia. O pedido foi feito por sua mãe, que precisava dele para ajudá-la com as plantações, depois da morte de seu pai. Ao chegar à comunidade, logo adquiriu grande prestígio no interior do grupo. Isso ocorre pelo fato de ele ter recebido uma boa educação fora da aldeia, podendo, assim, ajudar seu povo no diálogo externo à comunidade. Esta consideração valeu-lhe o cargo de chefia de seu ayllu tradicional. No decorrer de suas atribuições enquanto chefe do ayllu, Sebastián toma algumas decisões individuais, sem a consulta prévia a todos os moradores. Em uma das negociatas, a personagem acaba sendo passada para trás por um não índio, o que prejudica todos os moradores do ayllu.

A chefia nas comunidades Aymara é exercida pelos representantes que são eleitos anualmente pelo voto da aldeia. Tronar-se chefe é sinal de prestígio, confiança e respeito do grupo; trair essa confiança significava o desvencilhar-se da comunidade. Como escreveu 
Hidalgo, “[...] os roubos, adultério, vadiagem, eram fortemente castigados. Procurava-se cumprir com o princípio do equilíbrio, caso contrário os infratores eram marginados de suas comunidades" (HIDALGO, 2006, p. 115). Sendo acusado de traição e roubo, a partir da estrutura social do seu ayllu, Sebastián foi expulso, retornando a La Paz.

Antes de darmos continuidade ao enredo do filme, consideramos oportuno apresentar alguns pontos importantes, utilizados pelo cineasta para destacar a Bolívia clandestina, problematizando as mediações culturais feitas pela personagem principal ao longo de suas relações cotidianas. Após, voltamos ao momento em que Sebastián retorna à cidade de La Paz, pois temos aí a trama que desenrola o filme.

O cineasta, para apresentar a Bolívia "clandestina", que vigora mesmo sendo esquecida, utiliza-se de elementos, tal como a musicalidade andina, o hábito de mascar folhas de coca, a cosmologia indígena, o contraste entre as vestimentas utilizadas pelos indígenas e as usadas pelos não índios nas cidades. As cenas vão levando o expectador para o universo existente na prática dos hábitos tradicionais, dentro de um espaço permeado de relações etnocêntricas. Desta forma, mostra o drama vivido pelos indígenas que não são clandestinos, posto que estão em todos os lugares, mas que são mantidos na invisibilidade, sendo tratados como clandestinos na relação com a sociedade envolvente.

A representação do controle ideológico feito pela sociedade neocolonial no imaginário social sobre os conceitos de bonito/civilizado em contraste com o que é feio/selvagem também é tema exposto no filme. Essa temática é bem trabalhada em uma cena em que Sebastián sai de sua aldeia para ir à cidade de La Paz, e, estando ele com seu poncho nas mãos, entrega-o a sua esposa, negando-se a levá-lo, dizendo que a peça é reconhecida e discriminada pelos moradores da cidade como "cosas de indio". Neste contexto de dualidade, sua esposa, Basília, insiste para que ele leve o poncho, afirmando sabiamente a Sebastián: "Vos tienes que hacerte respetar. Acaso no eres hombre?"

A passagem leva-nos a pensar questões antropológicas e históricas que tocam as relações entre indígenas e a sociedade envolvente. Nesse sentido, o diálogo com González Casanova (2002, p. 96) faz-se necessário, pois, segundo este autor, "o racismo e a discriminação correspondem à psicologia e à política tipicamente coloniais" que se mantêm na edificação dos Estados-nações após suas independências. A construção de relações simbólicas de violências contra os grupos étnicos está nos olhares, nos discursos que denigrem esses povos cotidianamente. González Casanova (2002) chama nossa atenção para compreendermos que estes instrumentos foram utilizados pelos colonizadores e que ainda são 
utilizados, tendo em vista o estado de colonialismo interno que ainda permanece no interior dos antigos territórios coloniais.

Negar o pertencimento ao grupo étnico, que se constituiu culturalmente, para uma integração nas relações sociais em ambientes externos aos grupos indígenas, foi e ainda é uma prática corrente realizada por alguns sujeitos. Podemos fazer leituras da situação pela qual passa a personagem do filme, a qual representa milhares de indígenas na América. Dessa forma, sendo as identidades negociadas, frequentar um espaço urbano trajando vestimentas que destacam a tradicionalidade indígena - rechaçada pela sociedade não índia, sinônimo de constrangimentos e coações - forçava o indígena estrategicamente a negociar essa identidade/pertencimento.

O negar a identidade indígena, em determinadas conjunturas sociais, não significa o não pertencimento a determinado grupo étnico, mas sim uma estratégia encontrada por alguns indivíduos indígenas, tal como o caso de Sebastián em algumas passagens do filme, haja vista a convivência em locais colonialistas. Entretanto, o processo de negar o pertencimento étnico não é feito sem dramas internos nos sujeitos que precisam utilizar essas ferramentas.

Sebastián, estando em conflitos identitários, muda seu sobrenome Mamani, que o ligava ao seu ayllu, para Masmani, que não o caracterizava como indígena. Aqui também voltamos às circunstâncias psicológicas, antropológicas e também históricas que corroboram para esses dramas étnicos e identitários. Para continuar nossa discussão, apoiamo-nos em Fanon (2008), no livro: Pele negra, máscaras brancas, que discute a negação de negros à identidade negra, em situações coloniais. Para o autor,

Todo povo colonizado - isto é, todo povo no seio do qual nasceu um complexo de inferioridade devido ao sepultamento de sua originalidade cultural - toma posição diante da linguagem da nação civilizadora, isto é, da cultura metropolitana. Quanto mais assimilar os valores culturais da metrópole, mais o colonizado escapará da sua selva. Quanto mais ele rejeitar sua negridão, seu mato, mais branco será (FANON, 2008, p. 34).

Sebastián mudou seu nome, mas o fez dentro de uma sociedade colonialista que, ao longo de toda sua vida, sepultou sua originalidade cultural, sua indianidade, sobrando, assim, uma negociação identitária.

A relação desigual entre o universo indígena, que se constitui na relação com a sociedade envolvente enquanto clandestino, tendo em vista os silenciamentos impostos nas relações, é representada também por outras personagens no desenrolar do filme. Duas entre 
elas chamam a atenção: um jovem envolvido com a luta de resistência aos militares, que se encontra em fuga pela cordilheira, e um soldado que trabalha para a efetivação do golpe militar - lembrando que o pano de fundo do filme foi o golpe militar na Bolívia.

Uma das cenas retrata o jovem revolucionário, pertencente ao mundo não indígena, realizando uma fuga desesperada pela Cordillera dos Andes. Quando percebe a aproximação de alguns militares, pede ajuda para um grupo de índios Aymara que encontra no caminho. $\mathrm{O}$ pedido de socorro não é atendido, pois o grupo não compreende a língua falada pelo jovem. Conversando em língua Aymara, tentam compreender o que o jovem dizia, entretanto, não obtiveram nenhum sucesso. Sem entender os motivos do silêncio dos indígenas, uma vez que não falava a língua dos índios, o jovem diz, em espanhol: "índios de merda”.

Em outra cena, é apresentado o soldado boliviano, o qual retrata o desconhecimento e o desrespeito aos costumes indígenas. A cena ocorre quando Sebastián volta para seu ayllu, levando nas costas a máscara do Gran Señor Danzante. Nesse caminho, encontra pela Cordillera uma patrulha de militares que questiona os motivos pelos quais carregava aquela “estranha” máscara em suas costas. Sebatián prontamente explica ao militar que iria realizar o ritual do Gran Señor Danzante. A resposta não foi bem recebida pelo soldado, pois sua fala foi considerada sem nexo e sem veracidade.

Com essas passagens, o cineasta representa pequenos acontecimentos cotidianos das relações entre indígenas e não indígenas que reiteram a representação de uma sociedade clandestina, pois era também incompreendida em seus modos e costumes tradicionais. Sobre este debate, Hidalgo (2006) acrescenta que:

Muitas formas culturais andinas que são produtos tradicionais da cultura popular, não são cabalmente compreendidas pelas sociedades européias inclusive pelas sociedades urbanas locais, e estas se traduzem em más interpretações e tergiversações do sentido originário (HIDALGO, 2006, p. 104).

Nega-se o outro por seus elementos de diferenciação; nega-se o outro por sua relação cosmológica, territorial e cultural distinta do que a sociedade ocidental convencionou ser a correta. Todavia, essas situações, como observamos anteriormente, foram instituídas ideologicamente pelos colonizadores, para, assim, aniquilar os grupos étnicos e toda a alteridade que eles pudessem oferecer. Com as independências e a formação dos EstadosNacionais, mais uma vez os povos indígenas são ameaçados, uma vez que, conforme Dávalos: 
[...] esos pueblos poseen una forma de vivir, de pensar, de relacionarse que es diferente a aquella establecida como oficial y única, y se trata de un problema porque la práctica diaria de los estados, de los sistemas de representación política, de los marcos institucionales, de los códigos vigentes, se basa y se sustenta en una exclusión silenciosa, en una violencia sistemática y persistente (DÁVALOS, 2005, p. 21).

Os códigos dos aparatos governamentais, que são frutos do colonialismo e do etnocentrismo do período colonial, mas que mantêm as estruturas de um "colonialismo interno," impossibilitam a coexistência de diferentes grupos étnicos que sejam respeitados nas suas especificidades no interior de um Estado-Nação. Entretanto, atualmente, os movimentos indígenas têm buscado dialogar e combater essas estruturas excludentes.

Voltemos ao enredo do filme. Quando Sebastián é expulso de seu ayllu, este volta a viver na periferia de La Paz, trabalhando como marceneiro na construção de caixões funerários. Contextualizando a situação da personagem, temos uma trama de conflitos que perpassam a vida de Sebastián. O sentimento de exclusão do seu ayllu e a tristeza por não poder retornar, tendo de permanecer no ambiente citadino, onde era discriminado pela herança indígena, fazem Sebatían tomar uma decisão definitiva em sua vida: bailar ao Gran Señor Danzante.

Não encontramos muitas informações sobre este ritual, entretanto, tentamos estabelecer um diálogo entre as informações que o filme oferece e algumas leituras. No geral, os dados sobre o ritual Aymara do Gran Señor Danzante indicam que se trata de uma cerimônia em que um jovem da comunidade baila até morrer. Todo o ritual é acompanhado por um grupo de músicos que tocam para que este dance por dias, sem parar, até morrer por esgotamento físico. Sebastián havia acompanhado um jovem que bailou ao Gran Señor Danzante durante sua infância ainda no ayllu. Antes de sair de La Paz, encontrou um artesão que construiu a máscara para o ritual.

Como pontuamos no início do presente texto, o filme transita entre presente e passado. O enredo do filme apresenta-se enquanto presente na caminhada de Sebastían de La Paz até seu ayllu, após a decisão de bailar ao Gran Señor Danzante, percurso em que a personagem vai acionando suas memórias.

O cineasta consegue levar para o cinema uma história de conflitos e angústias dessa personagem indígena, que, ao longo de sua existência, teve sua vida marcada brutalmente por mentalidades coloniais, frutos de um colonialismo interno que procurou as anulações das tradições indígenas, que buscou o apagamento dos pertencimentos étnicos e que construiu 
nações clandestinas. Uma interpretação para esse desfecho da personagem é a possibilidade de um novo encontro com sua comunidade e com as tradições culturais Aymara. Assim, poderia se tratar de uma forma de reviver relações com seu ayllu, local onde nasceu e que o veria morrer, em uma dinâmica entre passado e presente.

\section{Para finalizar...}

[...] el pueblo boliviano ha resistido de diferentes maneras, y cuando no ha podido salir a las calles y campos a conquistar sus armas ha continuado elaborando su propia cultura de manera tenaz y obstinada en contraste con la clase dominante que habla castellano y piensa en norteamericano (SANJINES, 1977, p.1 - destaques nossos).

Na produção de Sanjinés, o contraste entre indígenas e não indígenas é latente, ao expressar para as telas aspectos das relações étnicas no interior da Bolívia da década de 1960. Fruto de um cinema crítico/social, o filme La Nacion Clandestina mostrou significativos elementos culturais de uma boliviana indígena anulada e transformada em clandestina. Ao objetivar um cinema feito juntamente ao povo, o cineasta Jorge Sanjinés conseguiu transpor para as telas do cinema códigos culturais dos Aymara, além de fazer uma incursão nos problemas e conflitos étnicos que perpassam a vida de indígenas que enfrentam conflitos de pertencimento identitários.

Não foi somente em territórios bolivianos que nos deparamos com a "clandestinidade" indígena; não foram os Aymara os únicos a sofreram com as violências simbólicas e humanas advindas do processo de colonização, mas sim os diferentes grupos étnicos distribuídos pelos três continentes. Povos que, no decorrer de seus processos históricos, se depararam com o contato de um povo que tinha no instinto de seu pertencimento a dominação de tudo que não fosse regido pela égide da Fé, da Lei e do Rei. Esses processos históricos culminaram nas situações atuais das nações colonizadas que, sendo frutos de um colonialismo interno, geraram uma situação social, política e econômica em que grupos étnicos são mantidos clandestinos em seus territórios ancestrais.

O filme sensibiliza para essas questões mostrando ao grande público os contrastes no interior de um Estado-Nação latino-americano. Mesmo que o filme tenha sido lançado há vinte e três anos e tenha retratado um período da década de 1960 da história social boliviana, sua temática continua sendo muito atual.

O estranhamento enquanto ferramenta de construção deve ser o primeiro passo para o reconhecimento, tendo em vista que não basta conhecer, precisa-se reconhecer as sociedades 
indígenas numa relação dinâmica e múltipla; assim, almejando a construção de espaços democráticos, onde nenhum setor da sociedade esteja em situação de clandestinidade, pois:

Um mundo que se outodefine como moderno e civilizado não pode aceitar conviver com essa ausência de democracia racial, cultural e política. Como se pode ser civilizado se não se aceita conviver com outras civilizações? Como se pode ser culto e sábio se não se conhece - e o que é bem pior - não se aceita conhecer outras culturas e sabedorias? Enquanto isso não acontece, continuamos convivendo com as contradições em relação aos povos indígenas (LUCIANO, 2006, p.35).

Essas palavras são profícuas e arrematam as reflexões que queríamos chegar com este texto, o qual partiu da análise de um filme para transitar sobre as identidades indígenas em situações de colonialismo interno. Nesse cenário, grupos significativos da sociedade são transformados em clandestinos pelo olhar que se cristaliza enquanto hegemônico de uma pequena parcela da população.

É possível percebermos que a clandestinidade da população indígena na Bolívia tem se transformado. No início do século XXI, o primeiro presidente indígena da América Latina foi eleito nesse país. Evo Morales torna-se, assim, uma possibilidade de mudança das estruturas do governo, de transformações que almejam a desconstrução da clandestinidade e a construção da visibilidade social/política e histórica dos povos indígenas. Conforme Pablo González Casanova (1996),

el proyecto de un Estado-nación que busca liberarse y enfrentar las condiciones de dependencia internacional y transnacional, difícilmente alcanzará sus objetivos si no reconoce la autonomía e identidad de las etnias de origen colonial como un derecho constitucional y constitutivo. (GONZÁLEZ CASANOVA, 1996, p.304)

Ao concordarmos com o autor citado e ao reiterarmos as mudanças que vêm ocorrendo nas estruturas governamentais, destacamos que são essas ações, juntamente com o movimento indígena, que possibilitarão as transformações sociais que trarão modificações no imaginário social. Ainda existe uma Bolívia clandestina, ainda existe um Brasil clandestino, ainda cruzamos com sujeitos históricos retratados no filme na personagem de Sebastián, mas podemos afirmar que um conjunto de fatores tem contribuído de maneira decisiva para o fortalecimento da autonomia indígena no interior dos Estados-Nacionais. 


\section{REFERÊNCIAS}

ANDRADE, Everaldo de Oliveira. A revolução Boliviana. São Paulo: UNESP, 2007, p.17.

BALANDIER, Georges. 1993 [1951]. "A noção de situação colonial”. Tradução de Nicolás Nyimi Campanário. Revisão de Paula Monteiro. Cadernos de Campo, São Paulo, 3:107-131. Disponível em: <http://www.fflch.usp.br/da/arquivos/publicacoes/cadernos_de_campo/vol3_n3_1993/cadern os_de_campo_n3_107-131_1993.pdf> Acesso em: 10 nov.2011.

DÁVALOS, Pablo. "Movimientos indígenas en América Latina: el derecho a la palabra". In: . (comp.). Pueblos indígenas, Estado y democracia. Buenos Aires: CLACSO, 2005.

FANON, Frantz. Pele Negra, máscaras brancas. Salvador: EDUFBA, 2008.

GONZÁLEZ CASANOVA, Pablo. Exploração, colonialismo e luta pela democracia na América Latina. Tradução de Ana Carla Lacerda. Introdução de Marcos Roitman Rosenmann. Petrópolis, Vozes; Rio de Janeiro, LPP; Buenos Aires, CLACSO, 2002.

HIDALGO, Max Antonio Arnsdorff. Comunidades andinas aymaras coexistência e modernização: A Nação Aymara contra a Nação boliviana. (Tese de doutorado em Planejamento Urbano e Regional, UFRJ). Rio de Janeiro, 2006. Disponível em: <www.ippur.ufrj.br/download/pub/MaxAntonioArnsdorffHidalgo.pdf> Acesso em: 30 de nov. 2010.

KORNIS, Mônica Almeida. História e Cinema: um debate metodológico. Rio de Janeiro. Revista estudos históricos, $1992 . \quad$ Disponível em: <www.cliohistoria.110mb.com/videoteca/textos/historia_cinema.pdf> Acesso em: 4 out. 2010.

LUCIANO, Gersem dos Santos. O índio brasileiro: o que você precisa saber sobre os povos indígenas no Brasil de hoje. Brasília: MEC/SECAD; LACED/Museu Nacional, 2006. (Coleção Educação Para Todos. Série Vias dos Saberes n. 1)

MURILLO, María Dolores Pérez; FERNÁNDEZ, David Fernández.(orgs.) La memoria filmada: América Latina a través de su cine. Madrid: IEPALA, 2002. Disponível em: <http://books.google.com.br/books> Acesso em: 20 de nov. 2010.

SANJINÉS, Jorge. Antecedentes históricos del cine social en Bolívia. 1977. Disponível em: < http://www.cinelatinoamericano.cult.cu/biblioteca/assets/docs/documento/498.pdf> Acesso em: 20 de nov. 2010.

STECZ, Solange Straube. Movimentos cinematográficos na América Latina. Curitiba: Revista Cientifica FAP. 2009. p. 196-207. Disponível em: <www.fap.pr.gov.br/arquivos/File/.../14_artigo_Solange_Stecz.pdf> Acesso em: 18 de nov. 2010 .

VILLARROEL, José Teijeiro. Regionalización y diversidad étnica cultural en las tierras bajas y sectores del subandino amazónico y platense de Bolivia. La Paz: Plural, 2007. 